The Curriculum Journal Vol. 14 No. 3 Autumn 2003 pp 371 - 388

\title{
Neuro-linguistic programming and learning theory: a response
}

\author{
Paul Tosey and Jane Mathison \\ Department of Educational Studies \\ University of Surrey
}

\begin{abstract}
In an earlier issue of this journal, Craft (2001) explored Neuro-linguistic Programming (NLP) in relation to a classification of learning theories. Craft also offered various observations on, and criticisms of, aspects of NLP such as its theoretical coherence, modelling, Dilts's 'logical levels' and possible dissonance of NLP's espousal of individuality in learning with its experiential emphasis.
\end{abstract}

This article offers a response to Craft's article. It describes the origins and nature of NLP, and explores its theoretical identity. NLP is portrayed here as based primarily on the cybernetic epistemology of Gregory Bateson $(1972,1979)$. The article offers a critique of many of the views put across in Craft's article, and builds on her attempt to position NLP theoretically.

The broad aims of this article are to offer an informed perspective on the nature of NLP; to extend the academic literature on NLP; and to develop debate about its relevance to the theory and practice of education.

\section{KEY WORDS}

Neuro-linguistic Programming; learning theory; modelling; cybernetics. 
The Curriculum Journal Vol. 14 No. 3 Autumn 2003 pp 371 - 388 
The Curriculum Journal Vol. 14 No. 3 Autumn 2003 pp 371 - 388

\section{INTRODUCTION}

Neuro-linguistic Programming (NLP), developed in the USA in the 1970's, has achieved widespread popularity as a method for communication and personal development, and is a recognised mode of psychotherapy in the UK. It is also being applied widely, if often informally, in UK education. To date, however, the academic community has shown little interest.

Craft (2001), ${ }^{1}$ in an earlier issue of this journal, attempts to locate NLP in relation to other theories and academic work. This is a welcome endeavour. However, in the light of our own knowledge and experience of NLP, we feel it is both urgent and important to make a critical response. We wish to offer our perspective on the nature of NLP, and to address the questions raised in Craft's article. In doing so we will take issue with several of its assertions.

As an overall observation, we are uneasy about Craft's reliance on so few, mainly secondary, sources for the article's understanding of NLP. Chief among these is O'Connor and McDermott (1996). This source is a useful introduction to NLP for general purposes, but insufficient for a scholarly review of the field. Of the fifteen citations in the reference list just one is an original work on NLP, and only passing reference to this is made in the article. Nor does the article consult any works that are regarded as significant influences on NLP (as cited in the text of this article). Equally we feel bound to remark on the tendency for Craft's article to make assertions and generalisations about the nature of NLP without clarification of the author's sources or authorities (for example, the account of 'modelling' : 131-2). Overall, we contend that closer scrutiny of original and wider sources on NLP is likely to yield a different perspective on many of the issues raised. 
Craft (125) poses five main concerns:

1 NLP's theoretical coherence (internally and in relation to existing theories); its status as a set of strategies rather than as a theory or model; and 'internal inconsistencies' which are an obstacle to it being regarded 'among the dominant learning theories of our age'.

2 The nature of modelling in NLP, especially 'how far copying an expert's behaviour can really lead to a learner becoming an expert', and the degree of attention to domain of application.

3 Whether there is dissonance between NLP catering 'to individuality in learning while also proposing a view that learning is best done experientially'.

4 Whether learners are 'really as predictable and as subject to cause/effect' as Dilts's 'theory' of logical levels would suggest.

5 The epistemological basis of NLP.

We address these questions after first describing the origins and background of NLP. The article ends with a summary of some criticisms of NLP, and of its potential applications in education.

As background on our own position and perspective, our discipline bases are education and management. We have trained in NLP, the first author to 'Master Practitioner' level in the UK (in 1992), the second beyond Master Practitioner level to acquire Trainer status (accredited by Richard Bandler). We have found NLP of immense value not only in our professional practice in higher education, but also as a topic for research, and as a prospective tool for qualitative research.

Our aim here is to provide a well-informed perspective on NLP. We intend to be 
The Curriculum Journal Vol. 14 No. 3 Autumn 2003 pp 371 - 388

balanced, open about the value we find in NLP as well as acknowledging criticisms and limitations. We believe that NLP holds great potential for education at all levels; we also acknowledge the need for research into, and critical evaluation of, NLP. Our broad intent is to help bridge the worlds of NLP and formal education. Thus while we do not claim to be neutral on the subject, neither do we consider ourselves overidentified with the world of NLP. We do not, for example, hold any public office or other position of power or responsibility within the NLP community.

\section{NEURO-LINGUISTIC PROGRAMMING: BACKGROUND}

Neuro-linguistic Programming (NLP) was developed at the University of California at Santa Cruz in the 1970s (Jacobson, 1994; McLendon, 1989). Its founders and principal authors were Richard Bandler, a mathematician and information scientist, and John Grinder, a linguist. Their partners, Leslie Cameron-Bandler and Judith DeLozier, also contributed significantly, as did other early developers such as Robert Dilts and David Gordon.

The term 'Neuro-linguistic Programming, coined by Bandler and Grinder, refers to purported systematic links between a person's internal experience (neuro), their language (linguistic) and their patterns of behaviour (programming). Despite the name and its connotations it has no direct connection to neuro-science, or to computer programming, although these were fields of interest to its developers ${ }^{2}$. NLP has been defined in various ways, often in its promotional literature as (for example) 'the art of communication excellence' or 'the study of the structure of subjective experience' (McWhirter, 1992). 
The Curriculum Journal Vol. 14 No. 3 Autumn 2003 pp 371 - 388

The first NLP publication was Bandler and Grinder's Structure of Magic: A Book about Language and Therapy (1975a; see also Grinder and Bandler, 1976), an attempt to identify patterns of communication that distinguished effective ('excellent') communicators from others. It was based on studies of, among others, Virginia Satir, a leading family therapist, and Fritz Perls, the founder of Gestalt therapy, whose skills Bandler and Grinder modelled. The outcome of this, NLP's 'meta-model', is distinctive in that it identifies language patterns that are believed to reflect basic cognitive processes. The meta-model is generally considered the core model of NLP. It is therefore surprising that Craft's article makes no mention of it.

Bandler and Grinder have long since gone their separate ways. Both remain active in the field, though Bandler trademarks his recent developments as 'Design Human Engineering' (DHE). Since the 1980s Grinder has concentrated on 'new code' NLP (DeLozier and Grinder, 1987), ${ }^{3}$ which takes an intentionally more holistic (i.e. whole body-mind) approach than the more analytical style of early NLP.

NLP has burgeoned into one of the world's most popular forms of interpersonal skill and communication training. The UK Association for NLP, for example, lists over 50 training organizations, and estimates that around 150,000 people (in the UK, we assume) had had some training in NLP by the end of the year 2000. ${ }^{4}$ NLP is used, whether explicitly or otherwise, by professional practitioners of many kinds - educators, managers, trainers, sales people, market researchers, counsellors, consultants, medics, lawyers and more. There are a number of competing NLP accrediting bodies or professional associations worldwide. In the UK, NLP is a recognized psychotherapy (assigned to the Experiential Constructivist Therapies section) accredited by the UK Council for Psychotherapy. ${ }^{5}$ In education, there is an enthusiastic UK NLP network called 'NLPEdNet'. ${ }^{6}$ There is interest too from associations such as the Society for Effective Affective Learning (SEAL). ${ }^{7}$ 
The Curriculum Journal Vol. 14 No. 3 Autumn 2003 pp 371 - 388

There is a limited, sporadic literature in several fields. These include education (Craft, 2001), training and development (e.g. Lee, 1993; Thompson et al., 2002; Trickey, 1997), accelerated learning (e.g. Sandhu, 1994; Stanton, 1994), counselling and psychotherapy (e.g. Geronilla, 1989), clinical psychology and hypnotherapy (e.g. Barnett, 1990; Field, 1990; Jupp, 1989), and management (e.g. Ashok and Santhakumar, 2002; Georges, 1996). Much of this literature explores applications of NLP to the field of practice in question.

Otherwise, publication in NLP has primarily been by and for those in the NLP community. There are numerous books by key developers (authors such as Bandler, Grinder, Dilts and others), and copious volumes communicating NLP more widely, of which O'Connor and McDermott (1996) is one example. The most comprehensive reference source is Dilts's Encyclopedia of Systemic NLP (2000). There has been one attempt at a journal in an academic style, NLP World, ${ }^{8}$ which was published from 1994 -2001. There are plans to relaunch it as a practitioner-oriented magazine, conceived of explicitly as 'the voice of NLP in the NLP community'. ${ }^{9}$

Academe appears relatively untouched by NLP. There has been a modicum of research interest from experimental psychology, consisting mainly of studies that examined NLP's 'eye movement' model (e.g. Baddeley and Predebon, 1991; Buckner et al., 1987; Dorn et al., 1983; Farmer et al., 1985; Poffel and Cross, 1985; Wertheim et al., 1986). These studies, many of which are summarized by Bolstad (1997), found no basis for acceptance of the model. It seems unlikely that a handful of unfavourable experimental studies accounts for this lack of academic interest. Possible reasons may include a 'chicken and egg' effect: NLP is not obviously the remit of any established discipline, so does not become mainstream. Another possibility is that NLP is not considered worthy of 'serious' study, whether because of its Californian origins, or a certain reputation as a 'manipulative' approach (though controversy might 
The Curriculum Journal Vol. 14 No. 3 Autumn 2003 pp 371 - 388

be expected to make it more, rather than less, attractive to research attention). Equally, there seems little incentive for NLP to build bridges with the academic world if this results in exposure to hostile theoretical interests or misunderstanding. To date, NLP seems most welcomed by informal practitioner networks (including teaching, as represented in NLPEdNet) that encourage direct use of NLP's strategies.

We do believe there is a need for research into NLP, for example in order to evaluate NLP through representing the views and experiences of those who have used it. With the relatively introspective nature of the NLP community, NLP 'users' sometimes seem to have little voice except when required as testimonials for trainers' publicity.

\section{THE COHERENCE OF NEURO-LINGUISTIC PROGRAMMING THEORY}

The first of Craft's questions is about the theoretical coherence of NLP, both internally and in relation to existing theories; and to what extent NLP is a theory, rather than a collection of models and/or strategies.

There is no doubt that NLP is eclectic, in that it draws from a wide range of sources. Thus within NLP one can detect influences from Gestalt therapy (Perls, 1969), personcentred counselling (Rogers, 1961), transformational grammar (Grinder and Elgin, 1973), behavioural psychology and cybernetics (Ashby, 1965), the Palo Alto school of brief therapy (Watzlawick et al., 1967), Ericksonian hypnotherapy (Bandler and Grinder, 1975b; Grinder et al., 1977), and, most importantly, the cybernetic epistemology of Gregory Bateson (Bateson, 1972).

What might this eclecticism signify? It probably needs to be viewed in the context of early statements from the originators of NLP dismissing interest in articulating or 
The Curriculum Journal Vol. 14 No. 3 Autumn 2003 pp 371 - 388

acquiring theory. For example, "We have no idea about the "real" nature of things, and we're not particularly interested in what's "true". The function of modeling is to arrive at descriptions which are useful.' (Bandler and Grinder, 1979: 7).

The claims to be disinterested in theory can also, we believe, be regarded as deliberately disingenuous and provocative. Bandler and Grinder's intent, perhaps, was to stay close to experience and avoid abstract discussion about the truths of human experience. As Craft points out, any practical method or principle for action, whether in teaching or elsewhere, necessarily has 'theory' behind it; the issue is simply whether that theory has been articulated. NLP places more emphasis on developing practical observational and listening skills, acquired through practice and apprenticeship, than on generating theory.

Bandler and Grinder were also extremely critical of the range of psychotherapies available in the USA which, as they perceived it, were rarely effective (i.e. in the sense of leading to change for individual clients), despite having a mass of intellectual frameworks. They strongly challenged the assumption that personal change necessarily involves long-term therapy, and is only possible with insight into one's past experience. In this respect Bandler and Grinder could be seen as offering a critique of North American 'shrink culture', and championing consumer-focused rather than professionled human services.

The state of NLP theory can also be seen as a consequence of the original claim to be a methodology or modelling process. Its theory is about the nature of models and modelling (Cameron-Bandler et al., 1985; Dilts, 1998a). In that sense it is theory substantially concerned with epistemology, ${ }^{10}$ where epistemology refers to the science of 'knowing' (Bateson and Bateson, 1988: 20; see also Bateson, 1991: 215-24). We return to the issue of modelling later, as this is related to one of Craft's questions. 
The Curriculum Journal Vol. 14 No. 3 Autumn 2003 pp 371 - 388

Thus NLP was led by a pragmatic, applied interest, not by a concern to develop theory. Bandler and Grinder were interested in figures such as Carl Rogers, Fritz Perls and Virginia Satir because of their reputation for excellence. There were other practitioners apparently informed by the same framework but with marked variation in effectiveness. Bandler and Grinder's question was, what was the 'difference that made a difference' between the excellent practitioners and the others? Almost selfevidently, this was not the formalised theory being used. Instead, they focused on patterns of communication and interaction - more the means and process through which the formal theory was mobilised and applied.

The theory of NLP was therefore regarded as an emergent by-product - moreover, in Bandler and Grinder's eyes, an inessential by-product - of application. However, does a theory need to be internally consistent in order to be valid? This seems a modernist more than a post-modern view. We suggest that NLP may be regarded as a transdisciplinary (Gibbons et al., 1994), in the sense that it innovates by drawing on sources from academe and from elsewhere. NLP in practice has been generated through application more than being deduced from axioms.

\section{NLP: UNDERLYING THEORETICAL ASSUMPTIONS?}

What (if anything) is the theoretical identity of NLP? Craft asks to which type or family of learning theory NLP seems to belong (though we note that this begs the question of whether NLP should be regarded as a learning theory at all). We agree in part with Craft's view that NLP 'draws on the fundamental assumptions of the theoretical framework of social constructivism' (131). This is consistent with NLP's assignment to the Experiential Constructivist Therapies section of the UKCP. 
The Curriculum Journal Vol. 14 No. 3 Autumn 2003 pp 371 - 388

However NLP, in our view, draws on aspects of all three groups of learning theory identified by Craft (128). Within NLP one can identify reflections of 'learning as growth' (e.g. in the broad belief in human potential, together with the influences from authors such as Perls and Satir); learning as 'association' (e.g. in the techniques of 'anchoring' see Bandler and Grinder, 1979); and learning as development and construction (e.g. reflected in the principle that we each construct our own maps of the world). As Craft says (and we concur), 'All teaching and learning are likely to involve elements of each theoretical perspective' (128 - 129).

NLP may be constructivist in its emphasis on the way people create, act according to , and can change and reconstruct, their own 'maps of the world'. Perhaps more important is that it is firmly systemic, or cybernetic, in its very strong interest in how such maps are constructed, utilized and change. This is central, in our view, to NLP's potential relevance to learning theory and processes of education.

There is no doubt in our minds, therefore, that NLP is properly described as primarily reflecting a systemic theory. For example, NLP explicitly regards a person as a whole mind-body system with patterned connections between internal experience ('neuro'), language ('linguistic') and behaviour ('programming'). As a paradigm of system behaviour, NLP adopts the TOTE (test-operate-test-exit) mode of functioning (Miller, Galanter and Pribram, 1960), which is significant in relation to learning. These processes depend on the dynamics of calibration and feedback (Wiener, 1965; Bateson, 1972). NLP is also predicated on the philosophical principle that systems demonstrate different logical levels (Russell, 1921), and the cybernetic principle that systems are based on information and characterized by feedback loops.

Craft does not mention this systemic core to NLP, although her article does refer 
The Curriculum Journal Vol. 14 No. 3 Autumn 2003 pp 371 - 388

indirectly to cybernetic principles through the quotation from Alder (1994; see Craft, 2001: 127). It also assigns what we regard as a fundamental cybernetic characteristic ('the notion of working through errors or "failures" as information', Craft, 131) to a constructivist orientation. Of course this may be a matter of debate. (Does one regard cybernetics as a subset of constructivism?).

Arguably the underlying theory of NLP is best represented in the work of Gregory Bateson. Bateson was not an NLP theorist himself but was consulted by the founders. Having enjoyed a long and eclectic academic career, and having made significant contributions to fields as diverse as anthropology, cybernetics and psychiatry (Bateson, 1972, 1979, 1991; Bateson and Bateson, 1988), Bateson was living in California. For a while he and Bandler were neighbours (close enough, apparently, for Bandler to hear Bateson typing). ${ }^{11}$

Bateson's views, perhaps explained most accessibly in Mind and Nature (Bateson, 1979) are strongly represented in NLP's core guiding principles, known as presuppositions (e.g. Dilts, 1998b). In NLP these constitute a worldview that is usually expressed aphoristically, and drawn from different sources. A typical list of operational presuppositions found in NLP training manuals, for example, is as follows:

- The map is not the territory (Korzybski, 1958).

- Mind and body are part of the same cybernetic structure.

- All behaviour is positively intended.

- People are making the best choice available to them in any situation.

- Every limitation presented to you is a unique accomplishment by a human being.

- There is no failure, only feedback. 
The Curriculum Journal Vol. 14 No. 3 Autumn 2003 pp 371 - 388

- The meaning of your communication is the response you get.

- Consciousness is a limited phenomenon.

According to this worldview, NLP assumes that people are inherently creative and capable, and also ultimately well intentioned. Communication happens through verbal and non-verbal channels, both consciously and unconsciously. People act according to the way they understand and represent the world, not according to the way the world 'is' (i.e. 'the map is not the territory'). Skills, beliefs and behaviours are all learnt, and consist of sequences of representations, therefore change and learning can be achieved through modifying such representations and sequences. NLP also assumes that functioning of which human beings are conscious, and which can be controlled consciously, represents only a small proportion of total functioning.

Thus while NLP literature generally does not articulate an underlying theory, it is possible to infer a theoretical coherence to NLP largely and essentially based on the axioms of Bateson's (systemic) perspective. We could, therefore, concur broadly with Craft's assertion that NLP is a set of strategies rather than a theory. However, according to the way Craft defines theory, NLP's presuppositions do supply 'fundamental assumptions which then underpin the workings of models of understanding' (130). To add to the confusion, in Craft's terms, it seems to us that NLP is a set of models, not just a collection of strategies. Craft herself cites Dilts's 'logical levels'; we referred above to the most fundamental NLP model, the 'metamodel' of language.

THE EPISTEMOLOGY OF NLP

Just before her concluding remarks, Craft interjects a surprising and unexamined 
The Curriculum Journal Vol. 14 No. 3 Autumn 2003 pp 371 - 388

statement. She suggests that 'the epistemological position of Neuro-linguistic Programming appears to be that reality "exists" out there' (133). Putting aside the question of whether this is a matter of epistemology or of ontology, we take issue most strongly with this.

NLP adopts Korzybski's dictum that 'the map is not the territory' as a common slogan. If treated very literally, the dictum implies that a 'territory' exists. However, we know of nothing in NLP that reinforces the idea of the existence of an independent outer reality. On the contrary, the entire epistemological thrust of NLP, following Bateson (e.g. 1972), is that it is the processes of perception and conceptualization (through language) that create individuals' experiences.

Two aspects of NLP are particularly relevant to this emphasis on how each person constructs their reality. These also expand on the way NLP 'relates words, thoughts and behaviours to purposes and goals' (126).

First, NLP considers that verbal reports may be literal accounts of people's inner experience. Thus when a person describes what they can 'see in their mind's eye', NLP assumes that the person is experiencing internal visual imagery (which may be outside their awareness). Furthermore, the qualities and characteristics of that imagery are significant, and relate in systematic ways to other aspects of that person's experience (e.g. feelings, beliefs, behaviour and so on). One of the most important beliefs from which NLP operates is that we use all our senses to code experience internally. The technical term for this is 'internal representation' (the word 'imagery' does not immediately conjure up the role of hearing, feeling, tasting, smelling and movement in the coding of experience).

How people use their senses internally, and the kinds of internal representations they 
The Curriculum Journal Vol. 14 No. 3 Autumn 2003 pp 371 - 388

create, are believed to be unique to every individual. NLP does not claim that there are universal regularities in the specific content or structure of such imagery (except that the senses are always used as an interior coding device) and so emphasizes the need to gather information about each individual's 'map of the world'. This has clear implications for the practice of teaching and learning and is in tune with a constructionist perspective.

Internal imagery ${ }^{12}$ appears in personal development (e.g. Glouberman, 1989), psychotherapy, sports psychology and elsewhere. What NLP adds is a systematic model of distinctions within that imagery, called 'submodalities' (Bandler, 1985; Bandler and MacDonald, 1988), which are thought to be related to physiological effects in the body; and an approach to how such images are connected in sequences of thought processes and related behaviour (know as 'strategies', Bandler and Grinder, 1979: 28).

The second key feature, building on Grinder's knowledge of transformational grammar (e.g. Grinder and Elgin, 1973; Bandler and Grinder, 1975a: Appendix A, $183-210$ ), is that NLP is predicated on the notion that individuals' patterns of language reveal some of their fundamental epistemological processes, their unique ways of mapping the territory of their experience and guiding action. NLP language models (the original meta-model and subsequent additions, e.g. Hall, 1989) identify natural language patterns that correspond to these epistemological processes.

Bandler and Grinder's approach to language has not yet, if the lack of citations in publications in linguistics and cognitive psychology is an accurate indicator, been scrutinized by academe. It does, however, appear to be supported in some respects by work in related fields (e.g. Talmy, 1985; Johnson, 1987; Fauconnier, 1997; Fauconnier and Turner, 2002). Chafe (1994), working in the field of Discourse 
The Curriculum Journal Vol. 14 No. 3 Autumn 2003 pp 371 - 388

Analysis, comes to a similar conclusion twenty years after the publication of the first book of Bandler and Grinder's.

This approach appears similar to the learning theory of Vygotsky (1939) who not only proposed a relationship between language and thought, but also that 'every thought tends to connect something with something else, to establish a relationship between two things' (Vygotsky,1939: 33). To our knowledge, Vygotsky is not referenced by Bandler and Grinder, so the relationship between NLP and Vygotsky's learning theory could be a relevant and fruitful line to explore.

\section{MODELLING AS REPLICATION}

Craft (131) questions the degree to which 'modelling' can enable replication of abilities. Craft relies initially (126) on O'Connor and McDermott's (1996) description of modelling. Later, however, modelling is described as 'pretending to be someone else', 'copying what one is aware of - often "surface" features of another person's behaviour' (131). This later material, in our view, misrepresents the nature of modelling.

As noted above, NLP claimed originally to be a methodology or modelling process. Jacobson (1994) explains:

The actual... methodology, that Bandler and Grinder used is known as human modeling...the addition of specific NLP technology makes it possible to discover much of what this human model does that he or she is not aware of. To do this well means to actually study the structure of people's thought processes and internal experience, as well as their observable behaviour. 
The Curriculum Journal Vol. 14 No. 3 Autumn 2003 pp 371 - 388

NLP insists that people re-create their experiences internally through all their senses, so that any approach to modelling must include investigation into both language patterns and the internal representations that sub-tend them (Bandler and MacDonald, 1988). The essence of modelling in NLP is to use its various frameworks (models) $)^{13}$ to construct a multi-perspective 'map' of a particular skill or quality. This is highly unlikely to result in identifying surface features only. Indeed, we suspect that with her emphasis on 'copying', Craft may be conflating 'modelling' in NLP with the more basic technique of 'mirroring'. ('In NLP, "mirroring" is the process of reflecting or feeding back physical patterns of behavior of another person': Dilts, 2000: 782.)

NLP, then, emphasizes the importance of identifying elements of the map that are essential to the skill. One well-known example in NLP, relevant to school education, is that of the 'spelling strategy' (Bandler and Grinder, 1979: 33). It is held in NLP that those who can spell effectively share a common internal strategy. Whether or not one accepts this claim, the strategy itself is an example of a very simple, streamlined 'model' that can be learnt by anyone.

Our experience is that modelling can provide a remarkably effective and streamlined way to learn some capabilities. However, it is quite possible for this approach to be over-simplified, especially on initial acquaintance, and to assume that all skills can be modelled in a straightforward manner.

We would have difficulty in commenting further, as Craft's argument at this point appears under-explained and possibly confused. She claims, for example, that NLP modelling involves copying 'someone else who is an expert performer'; then she says 'NLP, however, is much less concerned with the expert practitioner' (132). We do not understand what is meant by 'copying, without negotiation'. While there is little literature specifically about NLP modelling, Craft does not appear to have consulted 
The Curriculum Journal Vol. 14 No. 3 Autumn 2003 pp 371 - 388

the literature that does exist (in particular, Dilts, 1998a). While we agree in principle with Craft's point about the significance of context, ${ }^{14}$ we do not know on what basis she asserts that NLP 'gives no role to the domain of application' (132). No source, authority or evidence is cited to support this assertion.

A similar comment applies to Craft's argument regarding the experiential nature of NLP. First, the article states that NLP proposes 'a view that learning is best done experientially' (125), and 'is said to be "experiential'" (132). No source or authority is cited, nor does the article define what is meant by 'experiential' in this context. This is important because the term 'experiential learning' is problematic and varied in usage (Boud et al., 1993; Jarvis et al., 1998). While we would not dispute that in very broad terms NLP involves learning from experience, we are simply not sure what is being asserted or claimed here.

Finally in this section, the article implies that experiential learning is somehow in conflict with notions of learning styles. This seems an extraordinary suggestion, especially when one considers that Honey and Mumford's work is based on Kolb's (1984) 'experiential learning cycle' (Honey and Mumford, 1982: 3), which incorporates all four basic learning styles. That Craft's article assigns experiential learning to just one of Honey and Mumford's styles seems a confusion of logical types and further emphasizes the need to be more precise with the term 'experiential learning'. Craft then asserts that NLP is an approach which 'reflects the learning of "pragmatists" in particular' (132). There is no discussion of the grounds for, or validity of, this assertion. ${ }^{15}$ Whether or not the assertion has any merit is therefore impossible to assess.

The article's argument that there is dissonance between the claim that NLP caters to individuality in learning while also proposing a view that learning is best done experientially (in the abstract (125) and again in the conclusion (133)) appears to 
The Curriculum Journal Vol. 14 No. 3 Autumn 2003 pp 371 - 388

rely entirely on the passage we have just discussed. Regrettably, we cannot see how the argument as presented has enough substance to enable any meaningful response.

\section{LOGICAL LEVELS AS A THEORY}

Having argued that NLP is a set of strategies, we note that Craft refers to Dilts's 'logical levels' as a 'theory' (in the abstract (125)). Later, Craft refers to it as a 'model' (131). However it is labelled, the first question that arises is whether Dilts's 'logical levels' does hypothesize 'predictability and being subject to cause/effect' in the way that Craft suggests. It seems clear, based both on literature and on our first-hand experience of Dilts's teachings, that the 'logical levels' model is intended primarily as an abstraction and as a heuristic device. ${ }^{16}$

Again, Craft relies on a secondary source (O'Connor and McDermott, 1996). Dilts has surely published sufficient on this framework (Dilts and Epstein, 1995; Dilts, 1996; Dilts, 2000) to warrant original sources being consulted and cited. In this particular instance, too, we would recommend reference to Bateson's seminal paper, 'The logical categories of learning and communication' (in Bateson, 1972).

According to Dilts's encyclopaedia:

The concept of logical levels of learning and change was initially formulated as a mechanism in the behavioral sciences by Gregory Bateson, based on the work of Bertrand Russell in logic and mathematics. The term logical levels, as it is used in NLP, was adapted from Bateson's work by Robert Dilts in the mid-1980s, and refers to a hierarchy of levels or processes within an individual or group. The function of 
The Curriculum Journal Vol. 14 No. 3 Autumn 2003 pp 371 - 388

each level is to synthesize, organize and direct the interactions on the level below it. Changing something on an upper level would necessarily 'radiate' downward, precipitating change on the lower level. Changing something on a lower level could, but would not necessarily, affect the upper levels. (Dilts, 2000: 688)

This text does seem to imply a causal direction of change from upper to lower level. However, saying that change on one level will follow from change on another does not mean that this works deterministically. As an example, the principle is that a person's beliefs about learning (e.g. about how learning happens; about what it is and is not possible to learn; about how good a learner they perceive themselves to be; and so on) will influence both their ability to learn and their behaviour. A change in belief is likely to affect capabilities and behaviour. It is also possible, if less common, that a change in behaviour may trigger a change in belief. Using Craft's example (126), noticing that she had begun to catch a ball could have prompted the recognition, 'so I can catch a ball!' (belief about capability), and perhaps 'so maybe that means I am not stupid, after all' (identity).

Thus we understand Bateson and Dilts to be saying that a change at a higher logical level will necessarily have some effect at lower logical levels. But Dilts is not, so far as we are aware from the literature and from personal experience of his teaching, remotely suggesting that manipulations at belief level by a teacher will determine the responses the teacher would like to see at lower levels. The notion of logical levels is an aid to thinking about such issues, not a mechanistic technique.

\section{NLP, LEARNING THEORY AND CURRICULUM: BRIEF IMPLICATIONS}

We are delighted that Craft's article has attempted to bring NLP to the attention of a 
The Curriculum Journal Vol. 14 No. 3 Autumn 2003 pp 371 - 388

wider academic and practitioner audience. Debating NLP's relationship to learning theory seems a valuable and valid exercise. We have indicated several relevant theories so far, though we do not have the space to explore these relationships in detail.

As an example of a theoretical issue, NLP in our experience concentrates on the intrapersonal, intrapsychic processes of reality construction. It attends little, if at all, to the social context and intersubjectivity. If it is a learning theory, it is one that emphasizes individual rather than social learning. Craft identifies another possible line of enquiry when she asks how NLP relates 'to the dominant learning theories used to understand and facilitate the learning of children' (our emphasis). This is because NLP, to our knowledge, has no explicit developmental theory.

Nevertheless, NLP has much potential relevance for, and application to, the practices of teaching and learning. Again, this would need more space to explore further. As an indication, there are implications at various levels. One concerns the philosophy or theory underlying teaching, and the potentially profound implications of applying the underlying cybernetic epistemology to the practice of education. At the other extreme, where there is most evidence of uptake to date (see the NLPEdNet website, for example), is the level of technique. Here NLP may offer 'solutions' to many 'problems' encountered in teaching, for example to do with classroom management.

Both levels have implications for the training and development of teachers, and for curricula. We support Craft's view (130) that 'the role of theoretical underpinning is [being] degraded further and further in initial teacher education and in-service training'. The second author is currently conducting a doctoral study of the links between language and internal imagery, with reference to implications for teachers' use of language in educational settings. She is exploring at two levels: first, the 
The Curriculum Journal Vol. 14 No. 3 Autumn 2003 pp 371 - 388

differences in internal imagery that correspond to people's responses to microvariations in the wording of a question or statement; and second, a teacher's influence on students' beliefs about learning. This is, to our knowledge, the first formal study testing NLP's models of, and assumptions about, language patterns. She concludes that there are specific learning processes that are language mediated. The implications of this study for understanding ways in which teachers influence students' learning appear highly significant for the training of educators.

\section{SUMMARY}

In this article we have described the origin of NLP and discussed its theoretical base. While we appreciate Craft opening up debate about NLP, we have had cause to contest much of her article. The first of Craft's five main points seems the most fruitful to debate, especially in order to position NLP in relation to existing theories. Here our position is that NLP is certainly eclectic. To what extent it is coherent, and whether it should be regarded as a theory, a set of models or a collection of strategies, is open to debate. We have suggested that NLP could be regarded as a form of transdisciplinary knowledge. According to Craft's typology, NLP appears to draw on all three groupings of learning theory.

It is questionable whether it is appropriate to seek a high degree of internal theoretical coherence to NLP. We are not sure how important this question is - to whom does it matter, and for what purpose? No writers in the field appear to aspire to NLP being regarded 'among the dominant learning theories of our age' (125). Indeed, there seems to be no evidence that writers on NLP aspire to make it a formal theory at all. Nevertheless, we regard NLP as fundamentally, and reasonably consistently, based on principles of a cybernetic epistemology, especially as articulated by 
The Curriculum Journal Vol. 14 No. 3 Autumn 2003 pp 371 - 388

Bateson (1972, 1979).

We believe we have offered an explicit critique of Craft's other initial questions. Here we conclude by emphasizing our hope of enhancing understanding of NLP and its potential for education through scholarly enquiry.

\section{NOTES}

${ }^{1}$ Many subsequent references are from this same article. To avoid repetitious bibliographical detail we refer to page numbers only from now on. All other sources are cited in full.

${ }^{2}$ It is entirely separate from the field of 'Natural Language Processing' which also uses the acronym NLP

${ }^{3}$ see also http://www.nlpwhisperinginthewind.com/index.htm accessed 31.03.2003

${ }^{4}$ http://www.anlp.org/, accessed 31.03.2003

${ }^{5}$ http://www.psychotherapy.org.uk/, accessed 31.03.2003

${ }^{6}$ http://www.new-oceans.co.uk/ednet/index.htm, accessed 31.03.2003

${ }^{7}$ http://www.seal.org.uk/

${ }^{8}$ http://www.unil.ch/angl/docs/nlpworld/, accessed 31.03.2003

${ }^{9}$ http://www.nlpworld.com/magazine.asp?CategoryPagelD=1, accessed 31.03.2003

${ }^{10}$ Bandler has been heard to describe himself an epistemologist (personal communication).

${ }^{11}$ personal communication

${ }^{12}$ Which includes visual, auditory and kinesthetic dimensions

${ }^{13}$ including language patterns (the meta-model); strategies; meta-programmes and more.

${ }^{14}$ Grinder acknowledges this in an undated internet article, 'Sins of the Fathers', at http://www.nlpwhisperinginthewind.com/articles/sins.htm [accessed 31.03.2003]

${ }^{15}$ Our citation, above, of Bandler and Grinder (1975) seems to support the view that NLP as espoused embodied an `anti-theorist' stance.

${ }^{16}$ Dilts himself does hypothesise (Dilts 2000 p.670-1) links between these logical levels and 'neurological circuits'. 


\section{REFERENCES}

Alder, H. (1994) Neuro-linguistic Programming: The New Art and Science of Getting What You Want. London: Piatkus.

Ashby, W. (1965) An Introduction to Cybernetics. Methuen: London.

Ashok, S. and Santhakumar, A.R. (2002) 'NLP to promote TQM for effective implementation of ISO 9000'. Managerial Auditing Journal, 17(5): 261-5.

Baddeley, M. and Predebon, J. (1991) '"Do the eyes have it?": a test of neurolinguistic programming's eye-movement hypothesis'. Australian Journal of Clinical Hypnotherapy and Hypnosis 12(1): 1-23.

Bandler, R. (1985) Using your Brain for a Change. Moab, Utah: Real People Press. Bandler, R. and Grinder, J. (1975a) The Structure of Magic I: A Book about Language and Therapy. Palo Alto, California: Science and Behaviour Books. Bandler, R. and Grinder, J. (1975b) Patterns of the Hypnotic Techniques of Milton H. Erickson, M.D. Vol 1. Cupertino, California: Meta Publications.

Bandler, R. and Grinder, J. (1979) Frogs into Princes: Neuro-linguistic Programming. Moab, Utah: Real People Press.

Bandler, R. and MacDonald, W. (1988) An Insider's Guide to Sub-Modalities.

Cupertino, California: Meta Publications.

Barnett, E. A. (1990) 'The contribution and influence of neurolinguistic programming on analytical hypnotherapy'. Australian Journal of Clinical Hypnotherapy and Hypnosis 11(1): 1-14.

Bateson, G. (1972) Steps to an Ecology of Mind. London: Paladin/Granada.

Bateson, G. (1979) Mind and Nature. Glasgow: Fontana/Collins.

Bateson, G. (1991) A Sacred Unity: Further Steps to an Ecology of Mind, ed. by Rodney E. Donaldson. New York: Cornelia and Michael Bessie/Harper Collins. 
Bateson, G. and Bateson, M. C. (1988) Angels Fear .London: Rider Books.

Bolstad, R. (1997) 'Research on Neuro-Linguistic Programming' http://www.stant1.demon.co.uk/artcl007.htm, accessed 31.03.2003.

Boud, D., Cohen, R. and Walker, D. (eds) (1993) Using Experience for Learning.

Buckingham: Society for Research into Higher Education/Open University Press.

Buckner, M., Meara, N. M., Reese, E. J. and Reese, M. (1987) ‘Eye movement as an indicator of sensory components in thought'. Journal of Counseling Psychology 34(3): 283-7.

Cameron-Bandler, L., Gordon, D. and Lebeau, M. (1985) The Emprint Method. San Rafael, California: Future Pace.

Chafe, W. (1994) Discourse, Consciousness and Time: The Flow and Displacement of Conscious Experience in Speaking and Writing. Chicago: University of Chicago Press.

Craft, A. (2001) 'Neuro-linguistic Programming and learning theory'. The Curriculum Journal 12(1): 125-36.

DeLozier, J. and Grinder, J. (1987) Turtles All the Way Down: Prerequisites to Personal Genius. Bonny Doon, California: Grinder, DeLozier and Associates.

Dilts, R. (1996) 'The new leadership paradigm' (available online at: http://www.nlpu.com/archive.htm, accessed 31.03.2003).

Dilts, R. (1998a) Modelling with NLP. Cupertino, California: Meta Publications.

Dilts, R. (1998b) 'Presuppositions' (available online at:

http://www.nlpu.com/archive.htm, accessed 06.12.2002).

Dilts, R. (2000) Encyclopedia of Systemic NLP. Capitola, California: Meta Publications.

Dilts, R.B. and Epstein, T.A. (1995) Dynamic Learning. California: Meta Publications. Dorn, F.J., Brunson, B.I. and Atwater, M. (1983) 'Assessment of Primary Representational Systems with Neuro-Linguistic Programming: examination of 
preliminary literature'. American Mental Health Counsellors Journal 5(4):161-8.

Farmer, A., Rooney, R. and Cunningham, J. R. (1985) 'Hypothesized eye movements of neurolinguistic programming: a statistical artifact'. Perceptual and Motor Skills 61(3): 717-18.

Fauconnier, G. (1997) Mappings in Thought and Language. Cambridge: Cambridge University Press.

Fauconnier, G. and Turner, M. (2002) The Way We Think: Conceptual Blending and the Mind's Hidden Complexities. New York: Basic Books.

Field, E. S. (1990) 'Neurolinguistic programming as an adjunct to other psychotherapeutic/hypnotherapeutic interventions'. American Journal of Clinical Hypnosis 32(3): 174-82.

Georges D.P. (1996) 'Improved employee selection and staffing through meta programmes'. Career Development International 1(5): 5-9.

Geronilla, L. (1989) 'Neuro-linguistic programming compared to reality therapy'. Journal of Reality Therapy 9(1): 13-19.

Gibbons, M., Limoges, C., Nowotny, H., Schwartzman, S., Scott, P. and Trow, M. (1994) The New Production of Knowledge. London: Sage.

Glouberman, D. (1989) Life Choices and Life Changes through Imagework. London: Unwin Hyman.

Grinder, J. and Bandler, R. (1976) The Structure of Magic II: A Book about Communication and Change. Palo Alto, California: Science and Behavior Books.

Grinder, J. and Elgin, S. (1973) A Guide to Transformational Grammar. New York: Holt, Rinehart and Winston.

Grinder, J., DeLozier, J. and Bandler, R. (1977) Patterns of the Hypnotic Techniques of Milton H. Erickson, M.D. Vol II. Capitola, California: Meta Publications. Hall, C. (1989) The Language of Change. International Training Seminars, 7 Rudall Crescent, London NW3 1RS. 
Honey, P. and Mumford, A. (1982) The Manual of Learning Styles. Maidenhead: P. Honey.

Jacobson, S. (1994) 'Neuro-linguistic Programming', INFO-LINE, American Society for Training and Development, April (adapted version at http://sidjacobson.com/institute/history.html accessed 31.03.2003). Jarvis, P., Holford, J. and Griffin, C. (1998) The Theory and Practice of Learning. London: Kogan Page.

Johnson, M. (1987) The Body in the Mind: The Bodily Basis of Meaning, Imagination and Reason. Chicago: University of Chicago Press.

Jupp, J. J. (1989) 'Neurolinguistic programming: an experimental test of the effectiveness of "leading" in hypnotic inductions'. British Journal of Experimental and Clinical Hypnosis 6(2): 91-7.

Kolb, D. (1984) Experiential Learning: Experience as the Source of Learning and Development. New Jersey: Prentice-Hall.

Korzybski, A. (1958) Science and Sanity: An Introduction to Non-Aristotelian Systems and General Semantics. Lakeville, Conn.: The International Non-Aristotelian Library Publishing Company, the Institute of General Semantics (Distributors).

Lee, A. (1993) 'Outdoor education and Neuro-linguistic Programming'. Journal of Adventure Education and Outdoor Leadership 10(4):16-17.

McLendon, T. L. (1989) The Wild Days: NLP 1972 - 1981. Cupertino, California: Meta Publications.

McWhirter, J. (1992) Sensory Systems Training Manual. Glasgow: Sensory Systems. Miller, G.A., Galanter, E. and Pribram, K. (1960) Plans and the Structure of Behaviour. New York: Holt, Rhinehart and Winston.

O'Connor, J. and McDermott, I. (1996) Principles of Neuro-linguistic Programming. London: Thorsons.

Perls, F. (1969) Gestalt Therapy Verbatim. Moab, Utah: Real People Press. 
Poffel, S. A. and Cross, H. J. (1985) 'Neurolinguistic programming: a test of the eye-movement hypothesis'. Perceptual and Motor Skills 61(3): 1262.

Rogers, C.R. (1961) On Becoming a Person. London: Constable.

Russell, B. (1921) Introduction to Mathematical Philosophy, $2^{\text {nd }}$ edn. London: George Allen and Unwin.

Sandhu, D. S. (1994) 'Suggestopedia and Neurolinguistic Programming: introduction to whole brain teaching and psychotherapy'. Journal of Accelerative Learning and Teaching 19(3): 241-56.

Stanton, H. E. (1994) 'Suggestology and NLP: are there similarities?'. Journal of Accelerative Learning and Teaching 19(3): 241-56.

Talmy, L. (1985) 'Force dynamics in language and thought'. Papers from Parasessions on Causative Agentivity. Chicago: Chicago Linguistic Society, Chicago University Press: $293-337$.

Thompson J.E., Courtney, L. and Dickson, D. (2002) 'The effect of neurolinguistic programming on organizational and individual performance: a case study'. Journal of European Industrial Training 26(6): 292-8.

Trickey, K. V. (1997) 'How information gathering works for the librarian or the personal development coach'. Journal of Managerial Psychology 12(5): 352-6. Vygotsky, L.S. (1939) 'Thought and Speech'. Psychiatry 2: 29-54.

Watzlawick, P., Beavin, J.H. and Jackson, D.D. (1967) Pragmatics of Human Communication. New York: Norton.

Wertheim, E. H., Habib, C. and Cumming, G. (1986) 'Test of the neurolinguistic programming hypothesis that eye-movements relate to processing imagery'. Perceptual and Motor Skills 62(2): 523-9.

Wiener, N. (1965) Cybernetics or Control and Communication in the Animal and the Machine, $2^{\text {nd }}$ edn. Cambridge, Massachusetts: MIT Press. 
The Curriculum Journal Vol. 14 No. 3 Autumn 2003 pp 371 - 388 